\title{
Towards University Semester and Examinations Regulations Model Verification
}

\author{
Calorine Katushabe \\ MSc Information Systems \\ Dept. of Computer Science \\ Mbarara University of Science and \\ Technology
}

\author{
Nabaasa Evarist \\ Dept. of Computer Science \\ Mbarara University of Science and \\ Technology
}

\author{
Abubaker Nyanzi \\ Dept. of Information Technology \\ Mbarara University of Science and \\ Technology
}

\begin{abstract}
This paper reviewed the Mbarara University of Science and Technology semester and examinations regulations handbook and diagrammatically identified a number of flaws in the model. The next phase of this research is to identify parameters at each state in the model and redesign the model so as to try and eliminate or minimize the identified flaws by carrying out model checking for both the current model and the new model to be designed.
\end{abstract}

\section{General Terms}

University Semester and Examinations Regulations Model verification.

\section{Keywords}

Semester, Examinations, Regulations, Flaws, Model checking, Verification.

\section{INTRODUCTION}

A university needs regulations to define the relationships among its citizens, just as any society needs laws to govern the relationships among its citizens, in this case a university needs examinations regulations to govern its students and faculties. Accordingly, academic regulations stipulate the university's requirements for any award, and provide students with guidelines for achieving their personal academic goals.

According to [1] a university faces a responsibility not only to its own citizens but to the larger society as well, and thus its academic regulations must satisfy both internal and external needs and should not only clarify procedures and guarantee rights for students, but should also provide assurances to accrediting agencies, professional bodies, and society in general that standards are being maintained.

Mbarara University of Science and Technology (MUST) runs on a semester system and has semester and examinations regulations that governs its operations during the semester. These regulations lay down what is expected from the student throughout the semester and the entire academic year.

These regulations hint on registration, class attendance,

coursework, certificate of due performance, sitting examinations, malpractice, missing examinations, failing examinations, absconding from examinations, retaking an examination, being discontinued from the university and any others as shall later be shown in the current semester and examinations model.

The next phase of this research is to solve these flaws by model checking. In full generality, according to [2], [3] model checking is an automatic verification technique for large state transitions models. Model checking checks the correctness of a model in a finite state [4], [5]. Model checking is faster and is capable of providing diagnostic counterexamples which are useful for debugging [6], [7], [8].

Model checking is based on temporal logic, the idea of temporal logic is that a formula is not statistically true or false in a model, as it is in propositional and predicate logic. Instead, the models of temporal logic contain several states and a formula can be true in some states and false in others [9], [8].

\section{A CONCEPTUAL MODEL STIPULATING CURRENT SEMESTER AND EXAMINATION REGUALTIONS OF MUST}

Figure 1 shows a conceptual model that stipulates the current semester and examination regulations model of MUST.

The model was drawn based on written literature from a nonpublished but official document [10] from MUST. The question marks indicate that the state has hit a dead end or that has no beginning.

\section{RESULTS}

In this section results are discussed regarding the current semester and examinations regulations of MUST and the flaws that have been identified in them.

\subsection{Registration}

In the current semester and examinations regulations model as indicted in figure 1; a student is not supposed to exceed the maximum duration given to the program according to section 3.2 part $b$ of the semester and examination regulations booklet of MUST [10], a student who spends maximum duration allowed for a program before finishing gets discontinued from the university therefore in the model the time spent is tested against the maximum time of the program.

Right from the beginning of the model, if the duration (D) spent exceeds the maximum duration (max), the student gets discontinued from the university. If a student has not yet exceeded the maximum time, s/he continues and gets tested for the number of times s/he has attempted to do a particular examination. According to section 2.6.1 part d of the semester and examination regulations booklet of MUST, students are allowed only 3 times to sit for an examination. If the number of times has not exceeded three times a student is allowed to continue and register for a particular course unit in a given program 


\section{Conceptual Model of the Current Semester and Examinations Regulations of MUST}

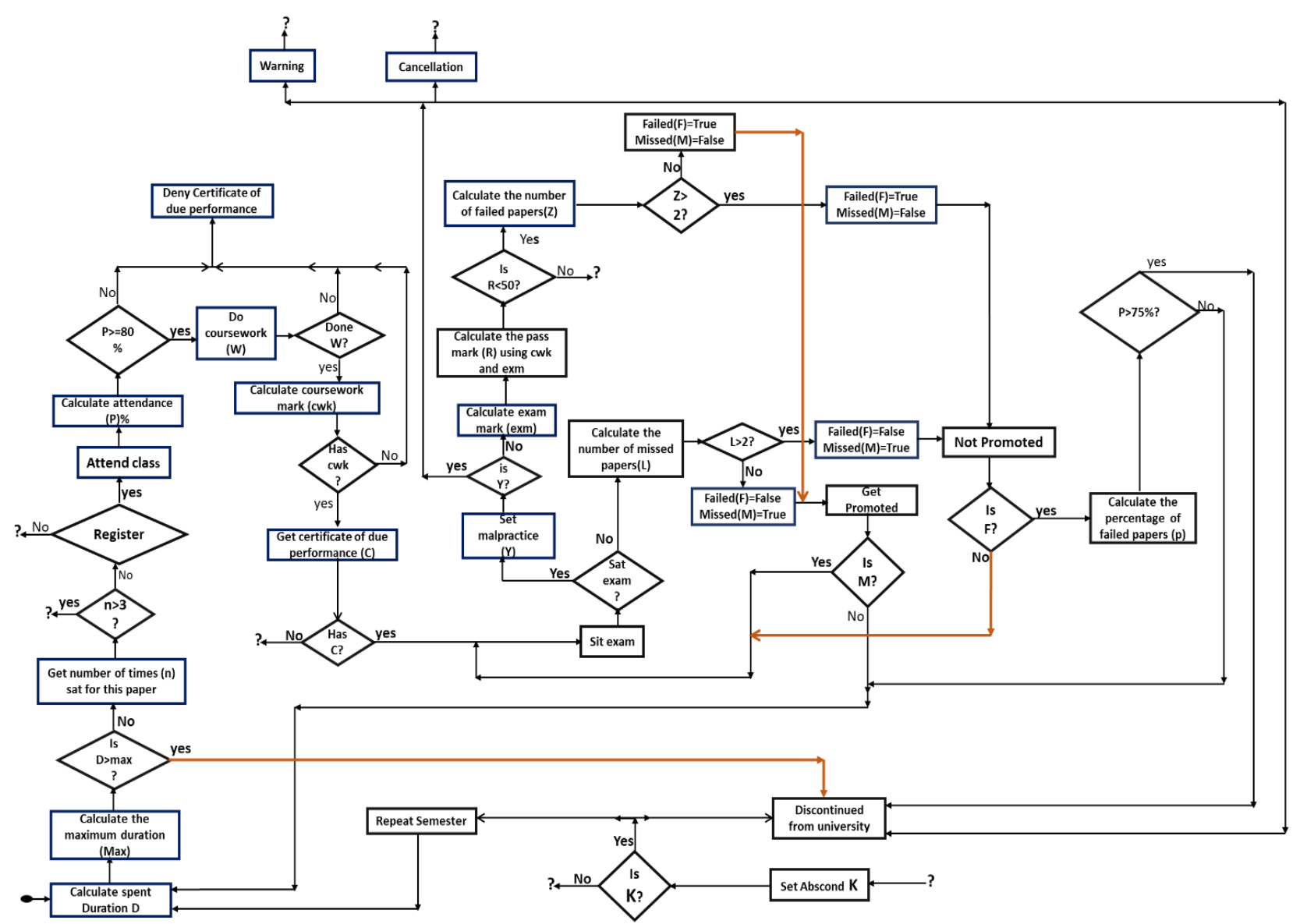

Figure 1: Current Semester and Examinations Regulations Model of MUST

\subsubsection{Flaws Identified at Registration State}

\section{i. Inconclusive Decision.}

The regulations do not specify what happens to a student who exceeds three times repeating a failed examination. In case a given student exceeds three times of repeating a failed examination, it will be the concerned authorities to decide what should happen to the student but not the regulations.

\section{ii. Automatic Registration.}

(a) Section 1.6 and section 2.6.1 part $\mathrm{f}$ of the semester and examinations regulations booklet of MUST just expect an already "registered student"; they do not clearly state that a student must register at each start of the academic year or semester. This means students can attend classes without registering.

(b) The regulations do not give a clear verdict for a student who fails to register. There is a need for the regulations to be clear on what happens to a student who does not register.

\subsection{Attending Class and Doing Coursework}

A registered student continues to attend class and does coursework in order to obtain a certificate of due performance which qualifies him/her to sit for the final examination. However according to section 2.3.1 of the semester and examination regulations booklet of MUST, the minimum class attendance in each course is constituted by attending at least $80 \%$ of the lectures, tutorials, and practical sessions.

Short of this, a student is denied a certificate of due performance according to section 2.3 of the same booklet.
Also if a student does not have coursework marks, s/he is denied a certificate of due performance according to section 2.3.2 of the same booklet.

\subsubsection{Flaws identified at Attending Class and \\ Doing Coursework state}

1. Denial of certificate of due performance

The regulations are quite on what happens to a student who has been denied a certificate of due performance because s/he has attained below $80 \%$ of the attendance.

2. Unset minimum pass mark for coursework

A minimum pass mark of the coursework is not given meaning someone with 0,1 or 2 marks in course works can go ahead to sit the final exam as long as s/he attended by $80 \%$ and did coursework but scored such miserable marks.

\subsection{Doing Final Examination}

Once a student has obtained a certificate of due performance, s/he qualifies to do a final examination, however at this point a student can either do or miss this examination.

Once a student does an examination, the final mark is computed with the coursework mark to obtain the pass mark. If the pass mark is or above $50 \%$ that means that a student has passed, otherwise the student has failed according to section 2.6 of the semester and examination regulations booklet of MUST. 


\subsubsection{Flaws Identified at Doing Final Examination State \\ i. Dead end}

Regulations are quite on a student who has passed, i.e. the regulations do not guide whether s/he has been promoted or not, this guarantees a dead end of a student who passes the examination in the current model.

ii. Unset minimum pass mark for the final examination

The minimum pass mark for the final examination is not set, that means that it's possible for a student to score $35 \%$ in coursework and $15 \%$ from the final examination and still pass, which may not be very logical for an academic institution.

\subsection{Examination Malpractice}

The punishment for malpractice ranges from a warning, cancelation of results to expulsion from the university according to section 2.4.9 part (g).

\subsubsection{Flaws Identified at Examination Malpractice} Unclearness of Examination Malpractice Penalty

1. The regulations are quite on what happens after the results have been cancelled i.e., does a student repeat or retake?

2. Regulations don't fully entail what warning means, whether after warning the marks are maintained or not and how many times can a student be warned.

\subsection{Missing examinations}

According to section 2.4.10 there are three categories of those who miss examinations

1. Those who miss not more than two examinations but qualify for a certificate of due performance.

A student who misses not more than two university examinations in an academic year but qualified for a Certificate of Due Performance is allowed to proceed to the next academic year but $s / h e$ is required to sit the examination(s) when they are next offered within the subsequent academic year. $\mathrm{S} / \mathrm{he}$ is not required to redo the course work.

2. Those who miss more than two examinations but qualify for a certificate of due performance.

A student who misses more than two university examinations in an academic year but qualified for a certificate of due performance is not be allowed to proceed to the next academic year. The student is required to sit the missed examination(s) when they are next offered within the subsequent academic year. The student is not required to redo the course work.

3. Those who abscond from university examinations. A student who absconds from university examinations is not allowed to proceed to the next Semester. S/he is required to repeat the entire semester.

\subsubsection{Flaws Identified at Missing Examinations State}

The regulations don't indicate that a student shall be assessed whether they have spent maximum duration for the program offered before sitting the missed examination.

The regulations don't indicate the maximum number of times a student is allowed to miss an examination.
The regulations don't indicate that a student should register for a missed examination when they are to redo it.

\subsection{On Absconding}

1. The meaning of absconding is not clear, is it when a student does not have/do course work or is it when one does not have/do final exam or both?

2. Regulation 2.4 .10 part (iii) and regulation 3.3 part (c) contradict themselves; that is, regulation 2.4.10 part (iii) states that a student who absconds from university examinations shall not be allowed to proceed to the next Semester and rule 3.3 part (c) states that a student shall be advised to discontinue his/her studies at the university if $\mathrm{S} / \mathrm{he}$ absconds from university examinations. Therefore it is not clear on what happens to a student who absconds.

\subsection{Other Areas}

The regulations need to include in an element where students are retaking course units in amidst a changed curriculum.

Do such students continue on the old curriculum or do they join the new one?

\section{CONCLUSION}

The identified flaws in semester and examination regulations at MUST are paramount, more flaws can easily be discovered with a model checker. The next phase of this research is to identify parameters at each state in the model and redesign the model so as to try and eliminate or minimize the flaws by carrying out model checking for both the current model and the new model to be designed. This verification will lead to a better model for MUST.

\section{REFERENCES}

[1] Amherst University, of Massachusetts, "Academic Regulations University of Massachusetts Amherst year 2015/2016," 2016.

[2] E. Clarke, K. McMillan, S. Campos, and V. Hartonas Garmhausen, ISymbolic model checking," in Computer Aided Verification, pp. 419-422, Springer, 1996.

[3] J. A. et al., \An overview of formal methods tools and techniques," Rigorous Software Development, Undergraduate Topics in Computer Science, vol. 10, no. 2,2011 .

[4] E. A. Emerson, IModel checking: A personal perspective," in ACM Turing award lectures, ACM, 2007.

[5] J.-P. Queille and J. Sifakis, ISpecification and verification of concurrent systems in cesar," in International Symposium on Programming, pp. 337-351, Springer, 1982

[6] E. M. Clarke, O. Grumberg, and D. Peled, Model checking. MIT press, 1999.

[7] R. Harish, IVerification by model checking," 2014.

[8] E. Clarke, H. Jain, and N. Sinha, IGrand challenge:Model check software," NATO Security through Science Series D-Information and Communication Security, vol. 1, p. $55,2006$.

[9] Z. Yang, C. Wang, A. Gupta, and F. Ivancic, "Mixed symbolic representations for model checking software programs," in Formal Methods and Models for CoDesign, 2006. MEMOCODE'06. Proceedings. Fourth 
ACM and IEEE International Conference on, pp. 17-26, IEEE, 2006.

[10] MUST, "Mbarara University of science and technology Examination Regulations." 2016.

[11] S. Chandra, P. Godefroid, and C. Palm, ISoftware model checking in practice: an industrial case study," in Proceedings of the 24th International Conference on Software Engineering, pp. 431-441, ACM, 2002.

[12] K. Havelund and T. Press burger, "Model checking java programs using java pathfinder," International Journal on Software Tools for Technology Transfer, vol. 2, no. 4, pp. 366-381,2000.
[13] W. Visser, K. Havelund, G. Brat, S. Park, and F. Lerda, Model checking programs,"Automated Software Engineering, vol. 10, no. 2, pp. 203-232, 2003.

[14] G. Brat, D. Drusinsky, D. Giannakopoulou, A. Goldberg, K. Havelund, M. Lowry,C. Pasareanu, A. Venet, W. Visser, and R. Washington, IExperimental evaluation of verification and validation tools on Martian rover software," Formal Methods in SystemDesign, vol. 25, no. 2-3, pp. 167-198, 2004.

[15] M. Musuvathi, D. R. Engler, et al., \Model checking large network protocol implementations." in NSDI, vol. 4, pp. 12-12, Cite seer, 2004. 